\title{
Evolution of local perforator flaps in lower extremity reconstruction
}

\author{
Rachel Cohen-Shohet, Mariel McLaughlin, David Kerekes, Harvey Chim \\ Plastic and Reconstructive Surgery, University of Florida, Gainesville, FL 32608, USA.
}

Correspondence to: Dr. Harvey Chim, Plastic and Reconstructive Surgery, University of Florida, P.O. Box 100138, Gainesville, FL 32608, USA. E-mail: harveychim@yahoo.com

How to cite this article: Cohen-Shohet R, McLaughlin M, Kerekes D, Chim H. Evolution of local perforator flaps in lower extremity reconstruction. Plast Aesthet Res 2019;5:28. http://dx.doi.org/10.20517/2347-9264.2019.030

Received: 15 Sep 2019 First Decision: 4 Nov 2019 Revised: 14 Nov 2019 Accepted: 19 Nov 2019 Published: 9 Dec 2019

Science Editor: Matthew L. Iorio Copy Editor: Cai-Hong Wang Production Editor: Jing Yu

\begin{abstract}
Lower extremity reconstruction is challenging for a variety of reasons. New techniques for soft tissue coverage continue to evolve. While free flaps are always an option, free flaps require significant microsurgical expertise, a proficient staff, advanced equipment, and a patient with a somewhat healthy baseline. However, as microsurgery has evolved, so has the identification of new anatomy and new techniques - namely, perforator based pedicled flaps. These flaps have expanded options for lower extremity reconstruction, and continue to advance the field of microsurgery. The purpose of this article is to review the evolution of perforator based pedicled flaps in the lower extremity, review the anatomy, and offer examples of design and indications.
\end{abstract}

Keywords: Perforator flaps, lower extremity reconstruction, soft tissue coverage

\section{INTRODUCTION}

Lower extremity coverage has long proved challenging for reconstructive surgeons primarily due to the paucity of soft tissue and skin available locally. Very often, lower extremity soft tissue injuries are complicated by associated bone, arterial, or nerve damage. Additionally, the lower extremities have a functional and mechanical component that further complicates the reconstructive process.

In the pre-microsurgery era, soft tissue reconstructive options were limited to tubularized flaps, popularized by Gilles, as well as the cross leg flap, originally described in a case report by Hamilton in

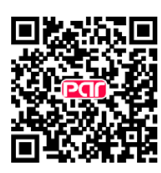


$1854^{[1]}$. It was not until 1971 that $\mathrm{Ger}^{[2]}$ published his techniques on rotation muscle flaps. In 1981, Pontén ${ }^{[3]}$ published his technique on fasciocutaneous flaps, showing that long narrow flaps, including the fascia, could be safely raised on the lower extremity. With a greater understanding of vascular anatomy, it was soon discovered that flaps could be safely based off of single septocutaneous or myocutaneous perforators.

Pedicled perforator flaps expand the possibility of coverage and salvage. They can be performed with basic surgical equipment and without need for microsurgery training. Additionally, they offer a quicker operative time, thus making them an option for nearly any patient, regardless of age and medical comorbidities. They also spare underlying musculature and vasculature, preserving in-line flow and therefore minimize morbidity.

The purpose of this article is to review the historical evolution and development of pedicled-perforator flaps for reconstruction in the lower extremity. Case examples are presented to illustrate the use of different flaps for coverage in the lower extremity.

\section{VASCULAR TERRITORIES}

Defining the vascular territories of the lower extremity has helped greatly in safe flap design. Fasciocutaneous flaps based on random pedicles for lower extremity reconstruction demonstrated high necrosis rates of up to $25 \%{ }^{[4]}$. With the careful anatomic study of cutaneous arteries and the emergence of the "angiosome" concept ${ }^{[5]}$, axial flaps were described all over the body. Some of this early work was performed by Salmon ${ }^{[6]}$, who in 1936 published his work on cadavers, mapping the entire cutaneous circulation. Taylor and $\operatorname{Pan}^{[7]}$ specifically evaluated the angiosomes of the leg. They determined that source vessels to the skin arise directly from arteries or their muscular branches, piercing the deep fascia in longitudinal rows at the intermuscular septum or alongside tendons. They also noted interconnections between vascular territories, and that, as vessels traveled down the leg, the perforators made a more direct course for the skin. Ultimately, they defined the territories of the popliteal, posterior tibial, peroneal, and anterior tibial arteries.

The introduction of perforasome theory further increased possibilities for flap design by introducing the concept of perforator flaps. This began with the deep inferior epigastric perforator flap described by Koshima and Soeda ${ }^{[8]}$, but many other flaps were subsequently described. There were many attempts to define perforator flaps ${ }^{[9]}$. Finally, in 2002, the Gent Consensus ${ }^{[10]}$ was published, defining what a perforator flap was, standardizing terminology, and offering examples. Saint-Cyr et al. ${ }^{[11]}$ defined the territories of perforators through an anatomic cadaveric study studying flaps over different territories. Flaps were injected with methylene blue dye for the dissection. Once the perforator was identified, contrast was injected to perform CT scans. Direct and indirect linking vessels were noted between perforasomes. Based on their anatomic study, they recommended that flaps should be designed in direction of linking vessels,in an axial direction.

The design and reliability of the perforator flap depends on the location of the perforating vessels and number of vessels included in the flap. Perforator flap design begins with understanding the anatomy based on the territories described above.

\section{Perforator territories in the lower extremity Posterior tibial perforators}

The posterior tibial artery is the continuation of the popliteal artery as it exits the popliteal fossa and is the largest terminal branch. It extends in an oblique and inferior direction into the lower leg, behind the tendinous arch of the soleus, spending the majority of its course behind the tibialis posterior after it gives 
off the peroneal artery ${ }^{[12]}$. Distally, it is located posterior to the medial malleolus and is divided into the medial and lateral plantar arteries. The posterior tibial artery supplies the posterior compartment of the leg.

The perforators from the posterior tibial artery are most commonly septocutaneous - between the flexor digitorum longus and the soleus muscle ${ }^{[13]}$. These perforators, concentrated at the middle third of the lower leg, are some of the largest of the entire lower extremity ${ }^{[12-15]}$. They are most readily identifiable $10-12 \mathrm{~cm}$ above the medial malleolus. However, flap design can occur anywhere up to $10 \mathrm{~cm}$ distal to the popliteal crease $^{[16-18]}$.

Historically, flaps based off the posterior tibial system included sacrifice of the main artery. The use of a perforator flap with preservation of the main vessel was described by Koshima et al. ${ }^{[19]}$, and its popularity quickly increased.

\section{Peroneal Artery perforators}

The peroneal artery takes its course off of the posterior tibial artery. From there, it descends through the posterior compartment of the leg, next to the posterior intermuscular septum ${ }^{[12]}$. Peroneal perforators, although not as numerous, remain another reliable vascular supply to a perforator flap. The perforators are located at the middle third of the fibula and are easily found with a Doppler. Schaverien et al ${ }^{[18]}$ found that musculocutaneous perforators emerge proximally from within the soleus or the peroneus longus muscles and septocutaneous perforators between the flexor hallucis longus and peroneus brevis muscles. Most of these perforators were found to emerge $13-18 \mathrm{~cm}$ proximal to the lateral malleolus. Distally, they found that these perforators often emerge superficial to the Achilles tendon ${ }^{[18]}$.

\section{Anterior tibial perforators}

The last main vascular territory to the lower extremity is supplied by the anterior tibial artery. The anterior tibial artery begins at the inferior border of the popliteus muscle. It passes anteriorly through a gap in the interosseus membrane and descends on the anterior surface of the membrane between the tibialis anterior and extensor digitorum longus ${ }^{[11]}$. It provides the blood supply to the anterior compartment of the leg. The major perforators from the anterior tibial artery are located proximally - documented $21-26 \mathrm{~cm}$ proximal to the intermalleolar line between the tibia and the tibialis anterior muscle ${ }^{[14,16]}$. These also happen to be the largest perforators. There is also a series of smaller perforators that emerge 4-9 $\mathrm{cm}$ above the intermalleolar line between the tendons of the anterior compartment; these supply the skin over both malleoli ${ }^{[2]}$.

\section{FLAP DESIGN}

While identification of appropriate vasculature was an important step in the evolution of perforator flaps of the lower extremity, flap design has also played a large role in the evolution of these flaps (including the need for vascular territories to be studied).

\section{V-Y perforator flaps}

V-Y flaps have been designed and utilized for reconstruction over the face, trunk, and extremities. Although first described based on a random pattern blood supply, they can also be designed along a single perforator. This increases the reach of the flap as well as the mobility when the flap is isolated on a single perforator. The primary benefit of the flap is decreased morbidity at the donor site, which in most cases can be closed primarily.

The flap is designed so that the length is twice the diameter of the defect to accommodate for longitudinal advancement ${ }^{[19,20-2]}$. A perforator can be selected via doppler location preoperatively. The skin, subcutaneous tissue, and muscle fascia are incised. 


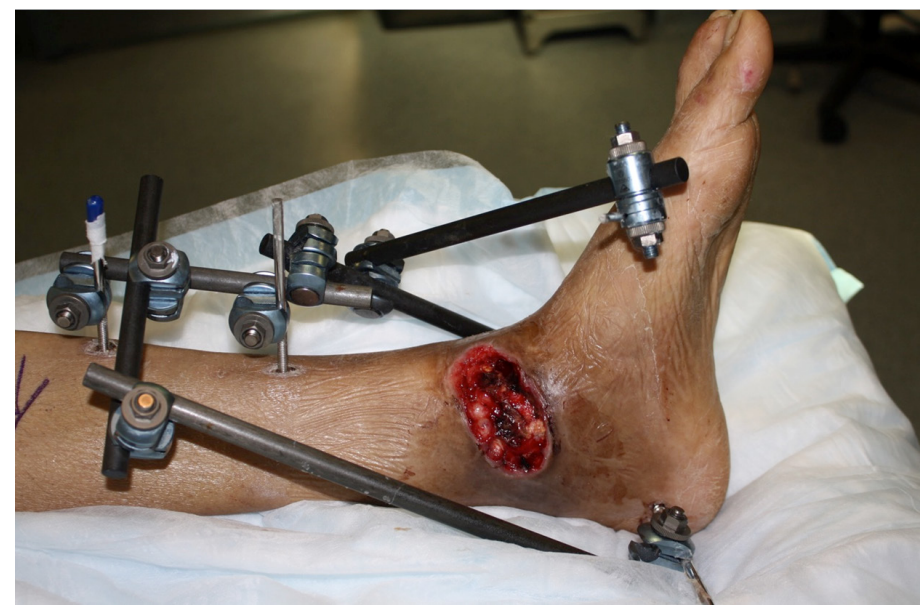

Figure 1. Left lower extremity traumatic wound on medial malleolus, after debridement and placement of external fixator

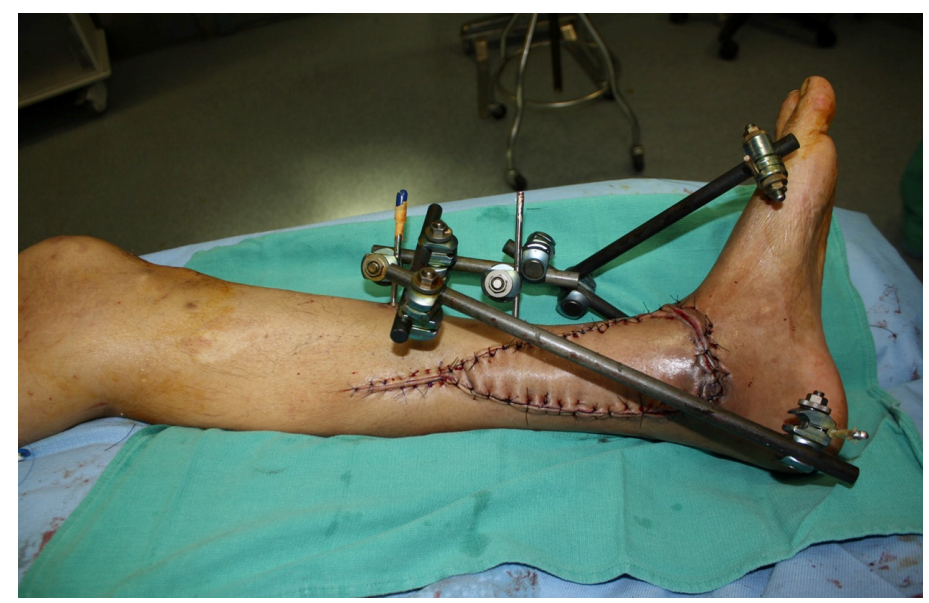

Figure 2. Immediately after $\mathrm{V}-\mathrm{Y}$ advancement flap and closure. Tension free closure achieved over the wound

Figure 1 shows a healthy young male involved in a trauma. He sustained an open fracture with a wound located over his medial malleolus. Closure was performed with a V-Y flap based on the posterior tibial artery. This was identified via Doppler, and the flap was elevated only on the perforator, which allowed increased mobility for closure of the defect. The flap is shown immediately post-operatively in Figure 2. There was complete tension free closure. Finally, the wound is shown one-month post-operatively in Figure 3. The wound healed without any complications and with good coverage distally.

\section{Propeller flaps}

In 1991, Hyakusoku et al ${ }^{[23]}$ published the concept of the propeller flap, which was described for scar release in the axilla and groin. Originally designed as a random pattern flap with a 90-degree arc of rotation, it had little utility in the lower extremity. However, as this idea emerged and was blended with the perforator flap concept, its application expanded to include coverage of wounds in the lower extremity.

Based on the Tokyo Consensus ${ }^{[24]}$, a propeller flap is now defined as an axial flap that reaches the recipient site through axial rotation. With a designated perforating vessel, a propeller flap indicates a flap that rotates anywhere 90-180 degrees along its axis with a "large blade" and a "small blade". The division between the blades is marked by the perforator. 


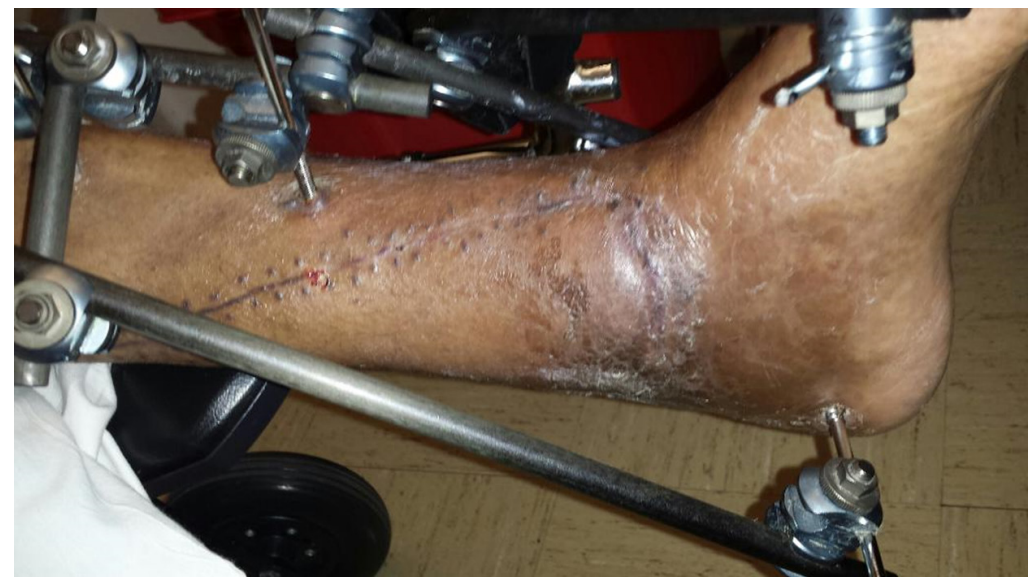

Figure 3. One-month post-operation: There is good healing over the wound without any distal necrosis

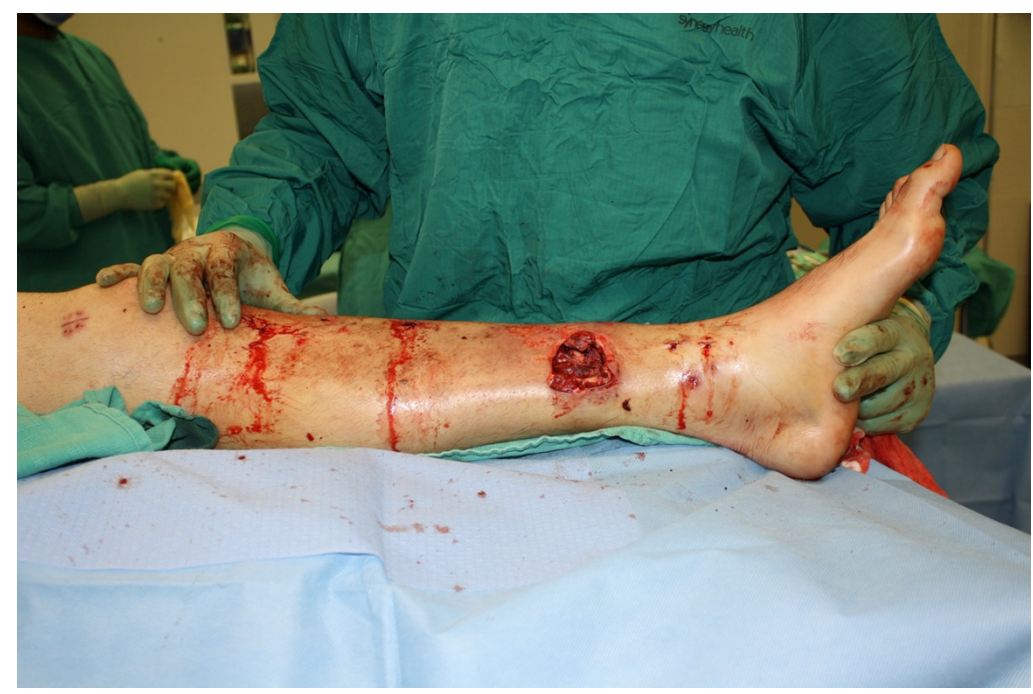

Figure 4. Traumatic wound of the medial lower third of the leg after debridement and operative fixation with intramedullary nail

Traditionally, the flap is designed along the axis of the limb, but the end can be modified to fit the skin defect. Although there are no absolute limitations of the length of the flap, it can be difficult to predict the perforasome perfused by the perforator. Investigators have attempted to define the safe skin territory perfused by a single perforator. One study found that the necrosis rate was six times higher in flaps designed more than $1 / 3$ of the limb length ${ }^{[25}$. Unfortunately, there is no clear way to predict necrosis at the tip of the flap and careful intra-operative and post-operative observations should be made, and secondary reconstruction should be considered if there is necrosis over vital structures.

Figure 4 shows a medial lower third wound after trauma. There is exposure of the tibia following intramedullary nail placement. To reconstruct this defect, a propeller flap was designed on the posterior tibial artery system. The entire flap was isolated on the perforator. The flap is shown elevated in Figure 5. Figure 6 shows isolation of the flap on the posterior tibial perforator. A skin graft was applied to the donor site. The flap is shown in Figure 7 at a follow-up appointment post-operatively, with complete viability and no distal necrosis. There is good coverage of the wound and the skin graft has taken well proximally.

The same applications can be applied to other perforators when designing propeller flaps. Figure 8 shows a lateral malleolar wound after a resection of a recurrent melanoma. There is exposure of the Achilles tendon 


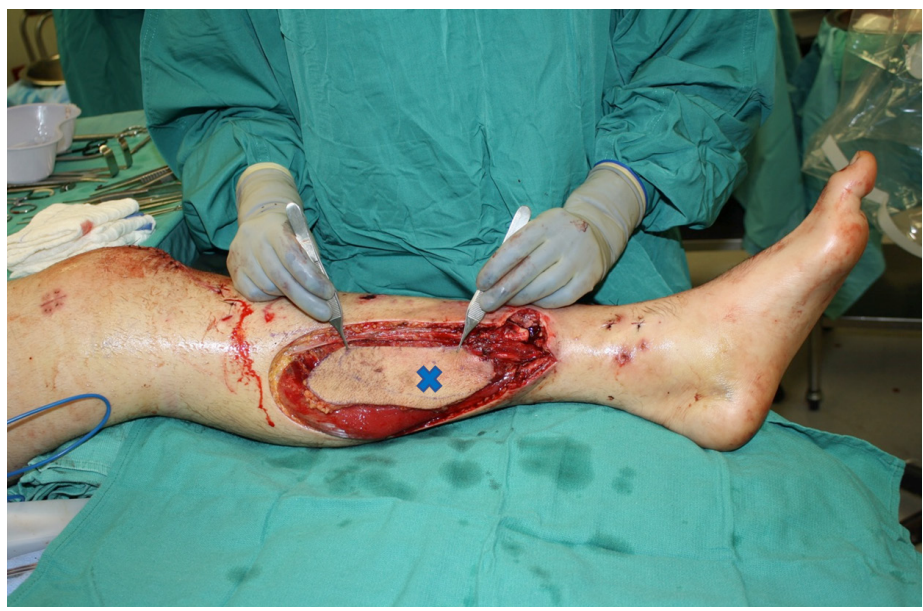

Figure 5. A propeller flap was designed on a posterior tibial perforator. The flap was isolated circumferentially on the perforator. The blue $\mathrm{X}$ marks the location of the perforator

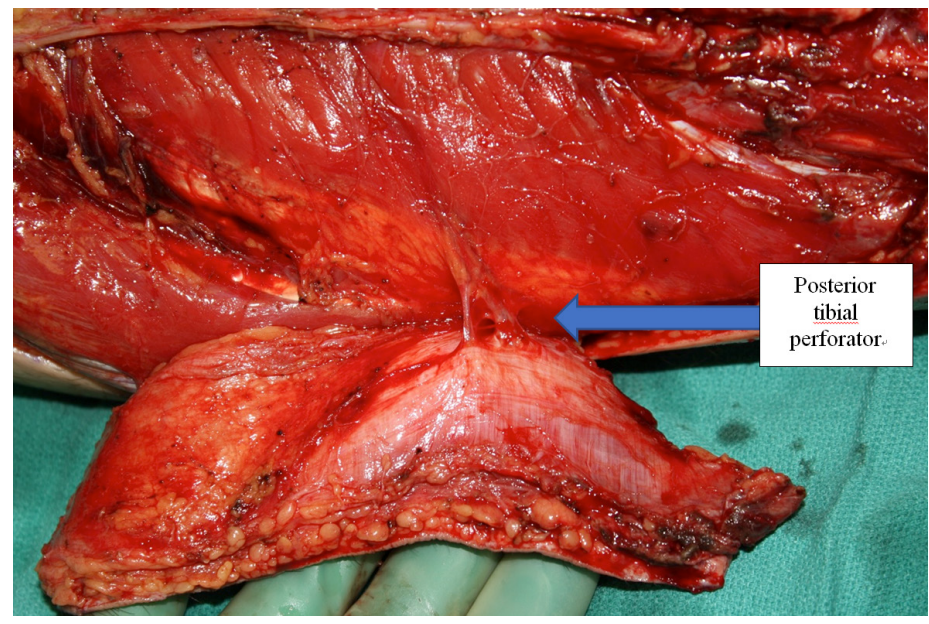

Figure 6. This shows the isolation of the flap in the subfascial plane on a large posterior tibial perforator

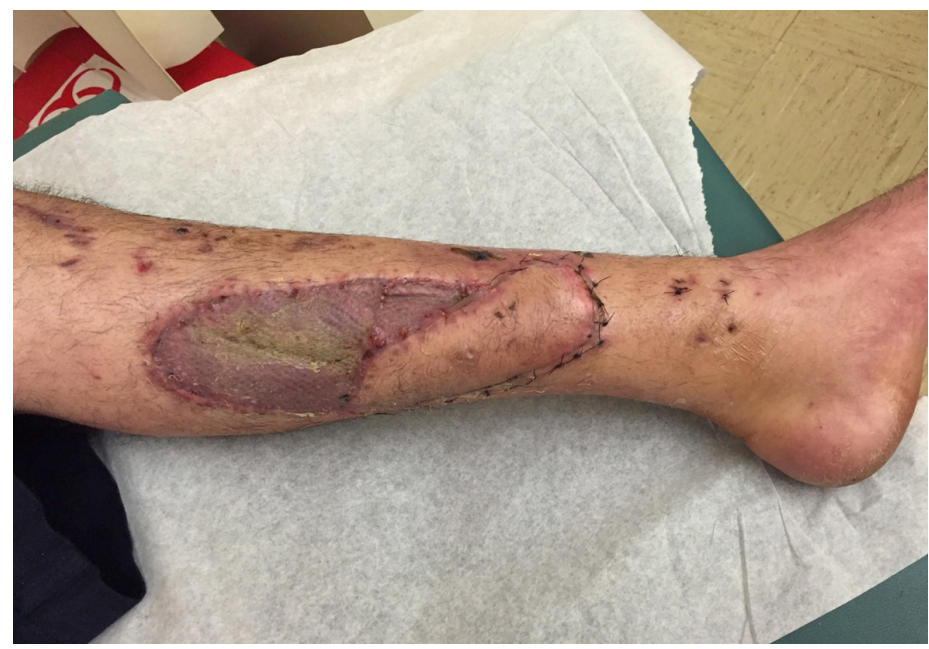

Figure 7. Post-operatively, good healing of the fracture site with no flap necrosis is shown. There is skin grafting to the donor site with good take 


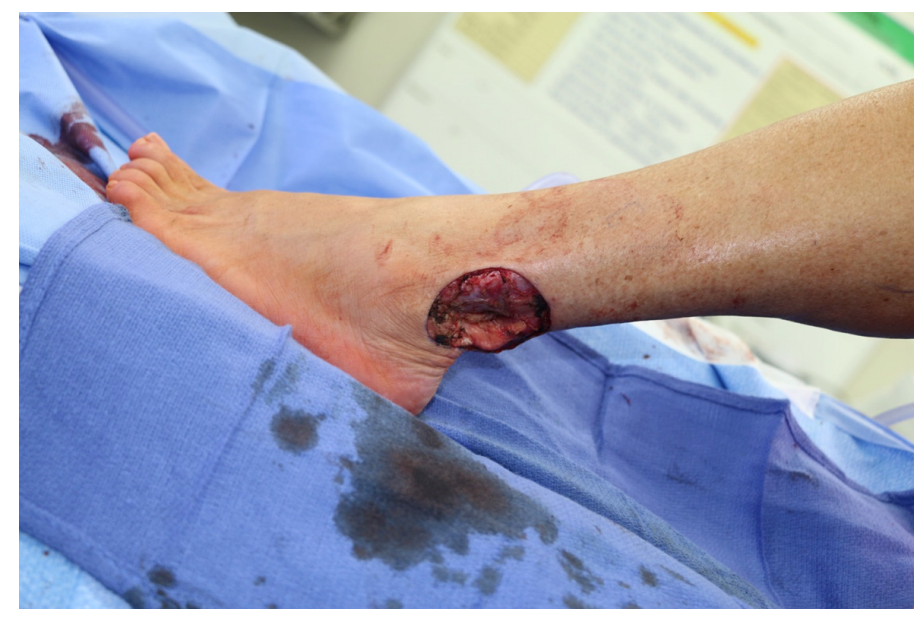

Figure 8. Lateral malleolar wound after resection of a recurrent melanoma

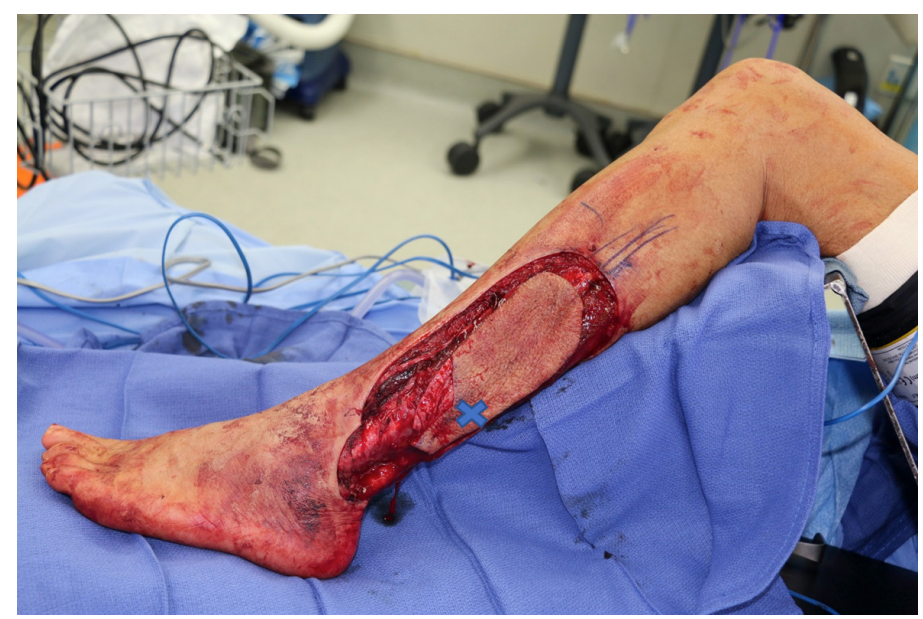

Figure 9. Large propeller flap was designed on the peroneal artery perforators. This was isolated on a single perforator and rotated into the wound. The blue " $X$ " denotes the location of the peroneal artery perforator

and lateral joint capsule. A large propeller flap was designed on the peroneal arteries [Figure 9]. This was rotated 180 degrees to fill the distal defect [Figure 10]. Figure 11 shows the flap healed post-operatively. There is good coverage over the joint, which is soft and supple and has full range of motion.

\section{Keystone flaps}

Although originally described for trunk defects, there is a limited but important role in lower extremity reconstruction. The keystone flap is based on fasciocutaneous perforators. The flap is designed so that each limb of the flap is 90 degrees from the longitudinal axis of the flap. This has been described throughout the literature for lower extremity defects mostly in the setting of oncologic reconstruction ${ }^{[26-28]}$ with good outcomes. Limitations of the keystone flaps include limited advancement and no rotational movement.

\section{Sequential perforator flaps: Kiss flap technique}

A persisting problem in lower extremity perforator flaps is the donor site. They often cannot be closed primarily and may require skin grafting, which can have negative cosmetic outcomes, especially in African American or Asian populations. The Kiss flap, described by Zhang et al ${ }^{[29]}$, is based on the goal of harvesting multiple skin paddles and rearranging them side by side for defect reconstruction. This then 


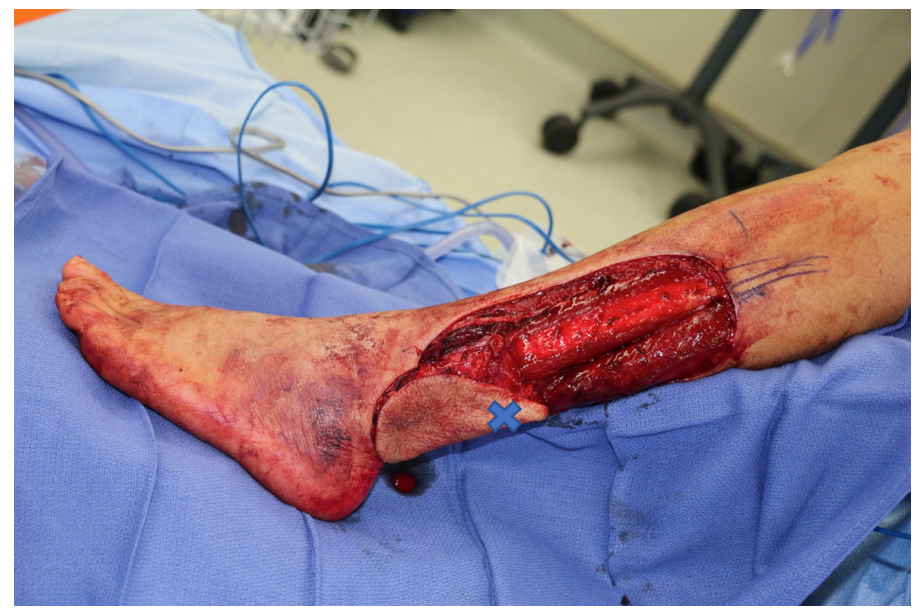

Figure 10. Peroneal artery perforator flap rotated 180 degrees into the wound. The blue " $\mathrm{X}$ " denotes the local of the peroneal artery perforator

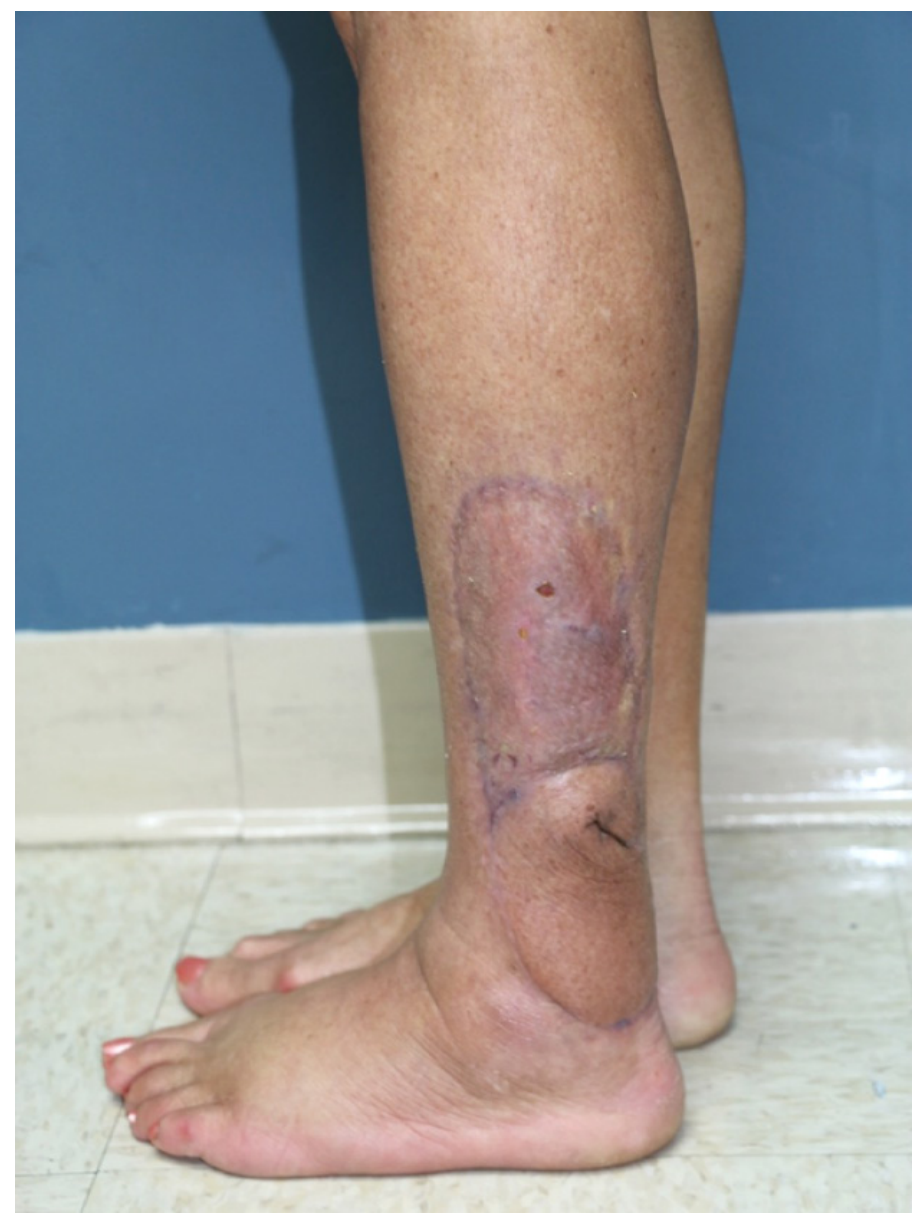

Figure 11. Peroneal artery perforator flap shown post-operatively. There is good healing of the flap and coverage of wound. The skin graft was placed on donor site and has healed well

allows for donor sites to be closed primarily. This group described five main types of flaps based on the vascular source. Different types may have important implications in the lower extremity, depending on the perforator location and choice of flap. 


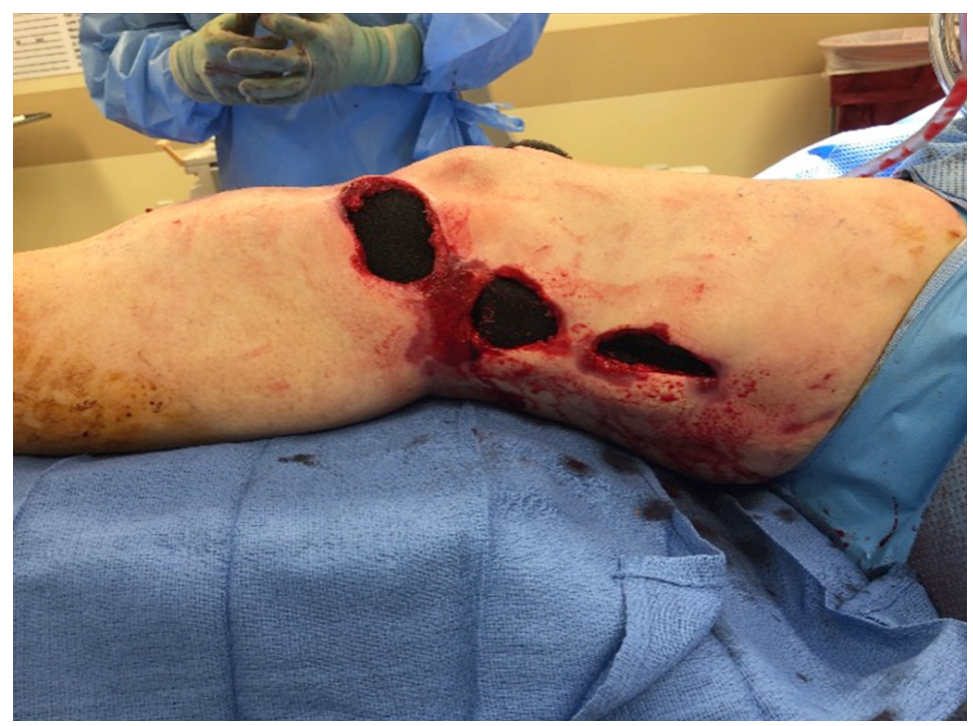

Figure 12. Traumatic wound of the left lower extremity after a motor vehicle collision. There were three separate wounds connected by skin bridges

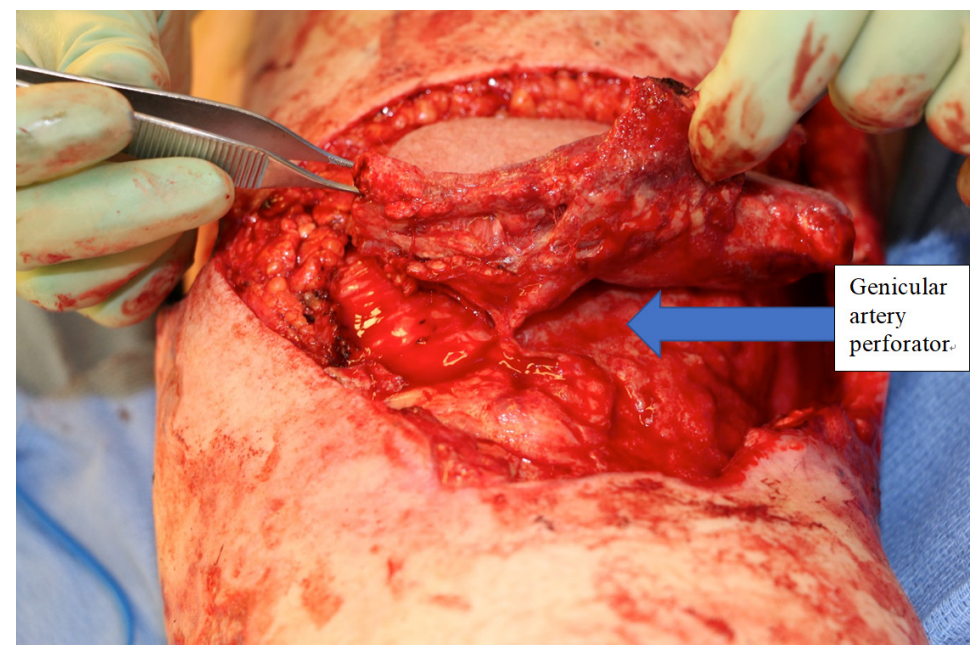

Figure 13. Freestyle propeller perforator flap designed off a superior lateral genicular artery perforator. The flap was isolated on the perforator and islandized

The benefits of the Kiss flap technique include improved donor sites with adequate soft tissue coverage. This often negates the need for grafting and therefore improves functional outcomes on the lower extremity, especially over joint surface. Shortcomings include complex design of flap and potential for tedious perforator dissections in order to receive adequate closure.

Figure 12 shows a 45 -year-old female after a motor vehicle collision with multiple traumatic injuries including an open left knee joint. After adequate debridement, there were three separate wounds on the lateral portion of the knee with significant soft tissue loss. First, a freestyle propeller perforator flap was raised based off a perforator from the superior lateral genicular artery [Figures 13 and 14], which was rotated inferiorly. To repair the secondary donor site and the more proximal parts of the defect, an anterolateral thigh flap based on a single perforator was raised and advanced distally in V-Y fashion to repair the donor site [Figure 15]. The patient had complete closure of all defects as well as the donor site [Figure 16]. 


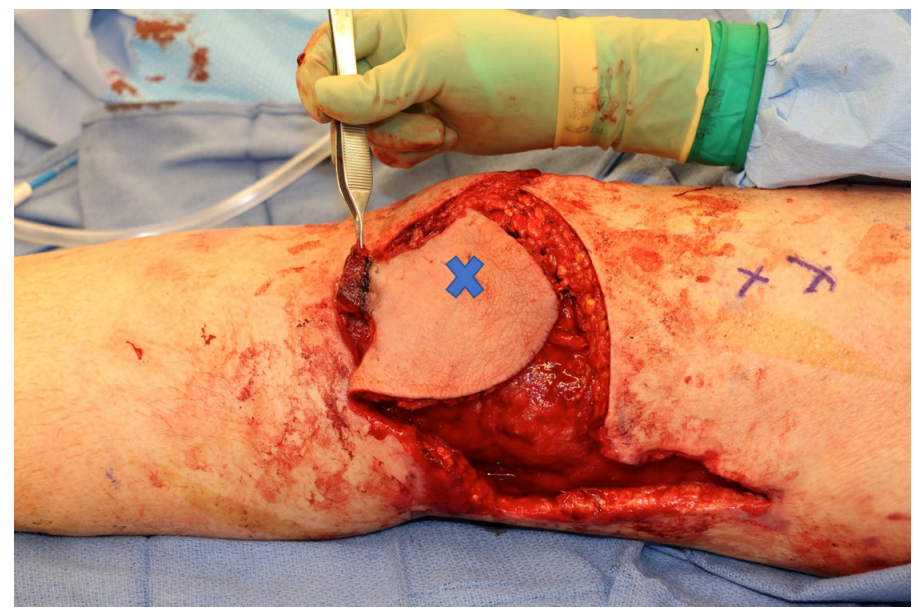

Figure 14. The flap was then rotated inferiorly into the first defect. The two other defects were connected. The blue " $X$ " denotes the location of the genicular artery perforator

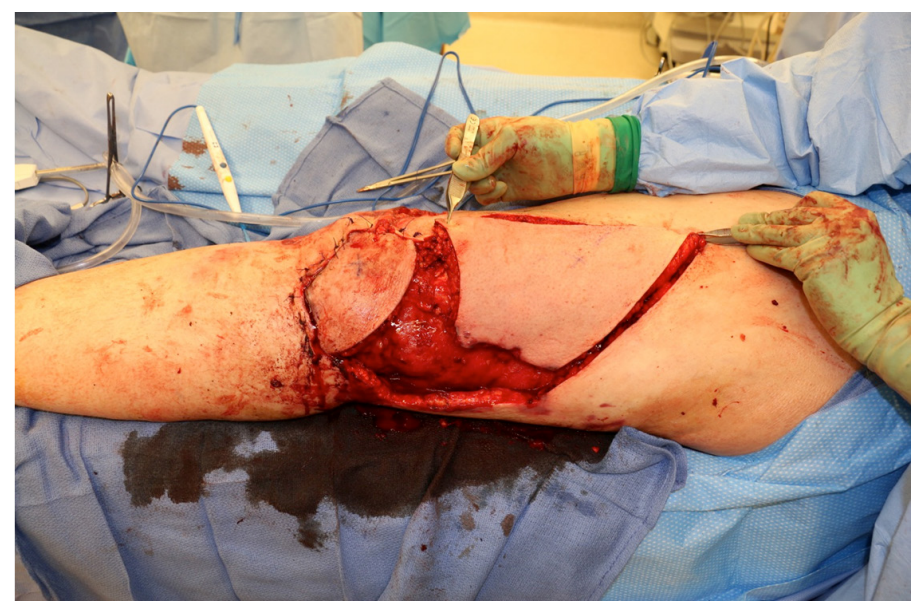

Figure 15. An anterolateral thigh flap was then elevated on a single perforator and advanced distally to close the two other connected defects as well as the donor site of the first perforator flap

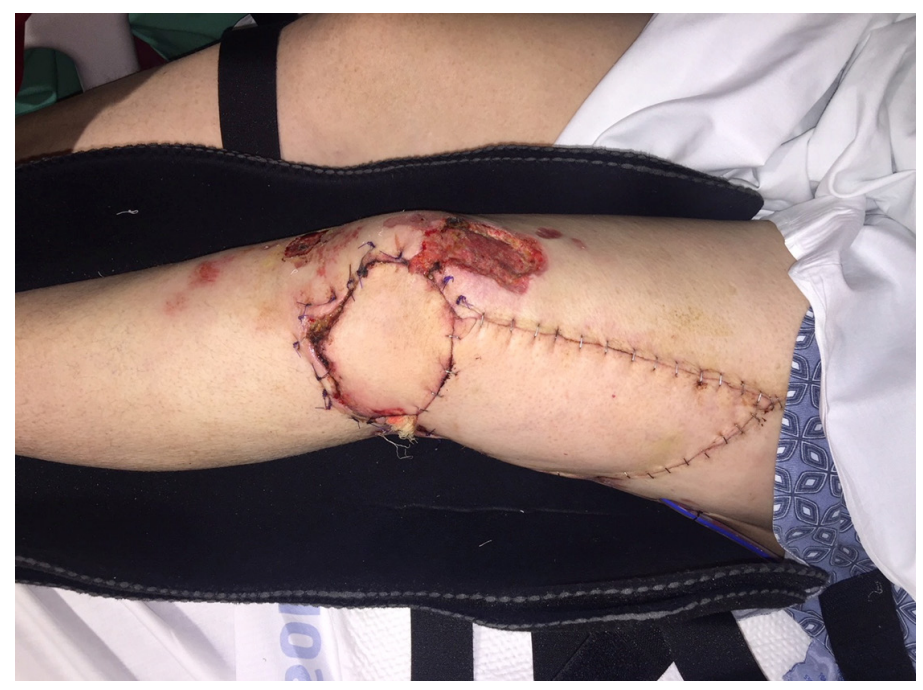

Figure 16. The patient is shown here two weeks post-operatively, with closure of defects and the donor site. In addition, she had a separate superficial thigh wound that was managed with local wound care, with complete healing 


\section{GENERAL CONSIDERATIONS}

For all perforator and propeller flaps of the lower extremity, the senior author offers several key points essential to maximize chances of success in reconstruction:

1. Preoperative imaging of the lower extremity to help identification of perforators. This can include CT angiography, utilizing thin cuts ( $\leq 1 \mathrm{~mm})$, color duplex, and Doppler.

2. Intra-operative use of tourniquets to the lower extremity to aid in dissection.

3. Minimizing tension by completely dissecting a visualized perforator free from surrounding tissue.

4. Do not extend propeller perforator flaps in the distal third of the leg beyond the junction of the proximal $1 / 3$ and distal $2 / 3$ of leg to reduce chance of partial necrosis.

5. Observe flap $10 \mathrm{~min}$ after rotating to confirm no kinking of pedicle and good perfusion after flap rotation.

6. A period of post-operative immobilization with splint to prevent undue tension and breakdown with excessive movement.

\section{LIMITATIONS OF PEDICLED PERFORATOR FLAPS}

While the benefits of perforator flaps have been listed above, there are several limitations. First while donor site morbidity related to a local or free muscle flap is decreased, local donor site morbidity remains. Skin grafting of the donor site is often required. The skin graft donor site may heal with a hypertrophic scar in some skin types. Wong et al. ${ }^{[30]}$ reported data on 61 pedicled-perforator flaps used for reconstruction of lower extremity defects with $50 \%$ of donor sites requiring skin grafts.

Another risk is flap necrosis. Gir et al. ${ }^{[31]}$ performed a systematic review of pedicle perforator flaps in 2012 that included 186 cases and reported an overall complication rate of $25.8 \%$ with the most common being partial flap loss (11.3\%). The overall failure rate was low at $1.1 \%$. Bekara et al. ${ }^{[32]}$ performed a meta-analysis of 428 perforator-pedicled propeller flaps and reported a similar overall complication rate of $25.2 \%$. The authors further went on to identify three significant risk factors: age greater than 60, diabetes, and arteriopathy. Although these reported risks are significant, the senior author's experience is that proper patient selection, preoperative imaging, and careful intraoperative evaluation of the flap intra-operatively can reduce risk of partial flap necrosis.

\section{CONCLUSION}

Lower extremity soft tissue coverage proves challenging to reconstructive surgeons due to the complexity of wounds and paucity of available local soft tissue. Reconstructive options continue to evolve, through skin grafts, local flaps and free tissue transfer and more recently pedicled-perforator flaps. Compared with free tissue transfer, they can be performed without advanced microsurgical training, with basic surgical equipment, and with minimal donor site morbidity. Perforator flaps provide the surgeon with flexibility in design as they can be based off of any of the three main vascular territories of the lower extremity. These flaps have proved to be both safe and efficacious and can be used to reconstruct smaller lower extremity defects without the need for free tissue transfer.

\section{DECLARATIONS}

\section{Authors' contributions}

Synthesized literature review, performed most of manuscript drafting: Cohen-Shohet $\mathrm{R}$ Contributed to literature review, manuscript formatting, and editing: McLaughlin M Assisted with formatting and final editing: Kerekes D Provided case series, expert knowledge, and final editing review: Chim $\mathrm{H}$ 


\section{Availability of data and materials}

Not applicable.

\section{Financial support and sponsorship}

None.

\section{Conflicts of interest}

All authors declared that there are no conflicts of interest.

\section{Ethical approval and consent to participate}

Not applicable.

\section{Consent for publication}

All photographs used had written formal consent.

\section{Copyright}

(c) The Author(s) 2019.

\section{REFERENCES}

1. Topalan M. A new and safer anastomosis technique in cross-leg free flap procedure using the dorsalis pedis arterial system. Plast Reconstr Surg 2000;105:710-13.

2. Ger R. The technique of muscle transposition in the operative treatment of traumatic and ulcerative lesions of the leg. J Trauma 1971;11:502-10.

3. Pontén B. The fasciocutaneous flap: its use in soft tissue defects of the lower leg. Br J Plast Surg 1981;34:215-20.

4. Quaba O, Quaba A. Pedicled perforator flaps for the lower limb. Semin Plast Surg 2006;20:103-11.

5. Taylor GI, Palmer JH. The vascular territories (angiosomes) of the body: experimental study and clinical applications. Br J Plast Surg 1987;40:113-41.

6. Salmon M. Artéres de la peau. Paris: Masson et cie; 1936.

7. Taylor GI, Pan WR. Angiosomes the leg: anatomic study and clinical implications. Plast Reconstr Surg 1998;102:599-616.

8. Koshima I, Soeda S. Inferior epigastric artery skin flaps without rectus abdominis muscle. Br J Plast Surg 1989;42:645-8.

9. Wei FC, Jain V, Suominen S, Chen HC. Confusion among perforator flaps: what is a true perforator flap? Plast Reconstr Surg 2001;107:874-6.

10. Blondeel PN, Van Landuyt KH, Monstrey SJ, Hamdi M, Matton GE, et al. The "Gent" consensus on perforator flap terminology: Preliminary definitions. Plast Reconstr Surg 2003;112:1378-82.

11. Saint-Cyr M, Wong C, Schaverien M, Mojallal A, Rohrich RJ. The perforasome theory: vascular anatomy and clinical implications. Plast Reconstr Surg 2009;124:1529-44.

12. Moore KL, Agur AMR, Dalley AF. Essential Clinical Anatomy. Lippincott Williams \& Wilkins; 2011.

13. Drimouras G, Kostopoulos E, Agiannidis C, Papadodima S, Champsas G, et al. Redefining vascular anatomy of posterior tibial artery perforators a cadaveric study and review of the literature. Ann Plast Surg 2016;76:705-12.

14. Wu WC, Chang YP, So YC, Yip SF, Lam YL. The anatomic basis and clinical applications of flaps based on the posterior tibial vessels. Br J Plast Surg 1993;46:470-9.

15. Zhang X, Wang X, Wen S, Zhu H, Ning Z, et al. Posterior tibial artery-based multilobar combined flap free transfer for repair of complex soft tissue defects. Microsurgery 2008;28:643-59.

16. Georgescu AV. Propeller perforator flaps in distal lower leg: Evolution and clinical applications. Arch Plast Surg 2012;39:94-105.

17. Schaverien MV, Hamilton SA, Fairburn N, Rao P, Quaba AA. Lower limb reconstruction using the islanded posterior tibial artery perforator flap. Plast Reconstr Surg 2010;125:1735-43.

18. Schaverien M, Saint-Cyr M. Perforators of the lower leg: analysis of perforator locations and clinical application for pedicled perforator flaps. Plast Reconstr Surg. 2008;122:161-70.

19. Koshima I, Moriguchi T, Ohta S, Hamanaka T, Inoue T, et al. The vasculature and clinical application of the posterior tibial perforator - based flap. Plast Reconstr Surg 1992;90:643-9.

20. Koshima I, Itoh S, Nanba Y, Tsutsui T, Takahashi Y. Medial and lateral malleolar perforator flaps for repair of defects around the ankle. Ann Plast Surg 2003;51:579-83.

21. Maruyama Y, Iwahira Y, Ebihara H. V-Y advancement flaps in the reconstruction of skin defects of the posterior heel and ankle. Plast Reconstr Surg 1990;85:759-64.

22. Venkataramakrishnan V, Mohan D, Villafane O. Perforator based V-Y advancement flaps in the leg. Br J Plast Surg 1998;51:431-5. 
23. Hyakusoku H, Yamamoto T, Fumiiri M. The propeller flap method. Br J Plast Surg 1991;44:53-4.

24. Pignatti M, Ogawa R, Hallock GG, Mateev M, Georgescu AV, et al. The "tokyo" consensus on propeller flaps. Plast Reconstr Surg 2011;127:716-22.

25. Panse NS, Bhatt YC, Tandale MS. What is safe limit of the perforator flap in lower extremity reconstruction? Do we have answers yet? Plast Surg Int 2011;2011:1-7.

26. Huang J, Yu N, Long X, Wang X. A systematic review of the keystone design perforator island flap in lower extremity defects. Med (United States) 2017;96:e6842.

27. John JR, Balan JR, Tripathy S, Sharma RK, Jadhav C. The keystone-design perforator-based flap for leg defects: a synthesis of philosophies. Plast Aesthetic Res 2014;1:70.

28. Riccio CA, Chang J, Henderson JT, Hassouba M, Ashfaq F, et al. Keystone flaps. Ann Plast Surg 2019;83:226-31.

29. Zhang YX, Hayakawa TJ, Levin LS, Hallock GG, Lazzeri D. The economy in autologous tissue transfer: Part 1. the kiss flap technique. Plast Reconstr Surg 2016;137:1018-30.

30. Wong JKF, Deek N, Hsu CC, Chen HY, Lin CH, et al. Versatility and "flap efficiency" of pedicled perforator flaps in lower extremity reconstruction. J Plast Reconstr Aesthetic Surg 2017;70:67-77.

31. Gir P, Cheng A, Oni G, Mojallal A, Saint-Cyr M. Pedicled-perforator (propeller) flaps in lower extremity defects: a systematic review. J Reconstr Microsurg 2012;28:595-601.

32. Bekara F, Herlin C, Mojallal A, Sinna R, Ayestaray B, et al. A systematic review and meta-analysis of perforator-pedicled propeller flaps in lower extremity defects: Identification of risk factors for complications. Plast Reconstr Surg 2016;137:314-31. 